\title{
AVALIAÇÃO DA SILAGEM DE MILHO E A QUALIDADE DO LEITE DOS PRODUTORES DA REGIÃO DE MORRINHOS GOIÁS
}

Karoline de Almeida Sousa, Andréia Santos Cezário, Jeferson Correia Ribeiro, Wallacy Barbacena Rosa dos Santos, Tiago Neves Pereira Valente, Aline Sousa Camargos, Eliandra Maria Bianchini Oliveira, Crislaine Messias de Souza

Instituto Federal Goiano, Goiás. Email: andreia.cezario@ifgoiano.edu.br

\section{RESUMO}

O leite de vaca é um alimento de alto valor nutritivo para dieta humana, porém, existe a necessidade de adequação com as normas sugeridas pela Instrução Normativa 62, para atender parâmetros de qualidade. Assim, objetivou-se avaliar a qualidade da silagem de milho e do leite, verificar se estão de acordo com a legislação vigente IN 62 e verificar a influência do nível de tecnificação de alguns produtores da região de Morrinhos Goiás. Foram escolhidas por acaso 10 propriedades da região, e aplicado um questionário para identificação do grau de tecnificação, classificado em Especializado (ES), Semi-Especializado (SE). Na mesma ocasião foram coletados em pontos distintos dos silos amostras de silagem para avaliação do $\mathrm{pH}$, matéria seca (MS), cinzas e proteína bruta (PB). Para avaliação da qualidade do leite foram quantificados contagem de células somáticas (CCS), contagem bacteriana (CBT), gordura e proteína. Foi verificado que as amostras de silagem estavam com porcentagem alta de cinzas, o que ocasiona perda na sua qualidade. Não houve diferença entre os níveis de tecnificação para proteína bruta. A CCS do sistema SE foi de 392.40 maior que no ES, a CBT obteve maior valor no ES. Todas as variáveis estão dentro dos limites exigidos pela IN 62.

Palavras-chave: Conservação, forragem, tecnificação

\section{EVALUATION OF MAIZE SILAGE AND MILK QUALITY OF THE PRODUCERS OF THE MORRINHOS GOIÁS}

\begin{abstract}
Cow's milk is a food of high nutritional value for human diet, however, there is a need to comply with the norms suggested by Normative Instruction 62, to meet quality parameters. The objective of this work was to evaluate the quality of corn silage and milk, to verify if they are in accordance with the current legislation IN 62 and to verify the influence of the level of technification of some producers of the region of Morrinhos Goiás. Of the region, and applied a questionnaire to identify the degree of technification, classified as Specialized (ES), Semi-Specialized (SE). At the same time silage samples were collected at different points in the silos to evaluate $\mathrm{pH}$, dry matter (DM), ash and crude protein (CP). Somatic cell counts (CCS), bacterial counts (CBT), fat and protein were quantified to evaluate milk quality. It was verified that the silage samples were with high percentage of ash, which causes loss in their quality. There was no difference between levels of gross protein technology. The CCS of the SE system was 392.40 higher than in the ES, CBT obtained higher value in ES. All variables are within the limits required by IN 62.
\end{abstract}

Keywords: Conservation, forage, technification 


\section{INTRODUÇÃO}

Duas características são marcantes na pecuária leiteira nacional. A primeira: a produção ocorre em todo território nacional; a segunda: não existe um padrão de produção. A heterogeneidade dos sistemas de produção é muito grande e acontece em todas as Unidades da Federação. Há desde propriedades de subsistência, sem técnica e produção diária menor que dez litros, até produtores comparáveis aos mais competitivos do mundo, usando tecnologias avançadas e com produção diária superior a 60 mil litros (ZOCCAL et al., 2011).

O leite, sem outra especificação, o produto oriundo da ordenha completa, ininterrupta, em condições de higiene, de vacas sadias, bem alimentadas e descansadas (BRASIL, 2011).

E considerado um alimento de alto valor nutritivo, fonte de proteínas, carboidratos, lipídios, vitaminas e sais minerais (ALMEIDA, 2013).

O foco principal do setor leiteiro é fornecer à população leite com qualidade de forma que a atividade seja rentável aos produtores envolvidos. Para alcançar tais objetivos torna se importante adotar controles e estratégias em todo o sistema produtivo, envolvendo, portanto, as propriedades rurais, os laticínios, a distribuição, o varejo e a legislação pertinente ao setor (FERNANDES, 2011).

Para uma produção leiteira eficiente e de qualidade o produtor precisa se preocupar desde a nutrição do gado, pois a dieta influencia na composição do leite de acordo com Dias 2006, até a destinação final de seu produto na indústria.

Uma situação que preocupa os produtores é o que oferecer ao gado durante o período da seca, que não inviabilize a produção e a qualidade, mantendo a composição nutritiva, considerando que nesta que época do ano as pastagens tornam se deficientes. Uma alternativa seria usar alimentos conservados como a silagem de milho, que segundo Oliveira, 2007 vem sendo uma das melhores opções de suplementação no período da seca.

Outras situações além da dieta devem ser levado em consideração para obtenção de um produto de qualidade, a higienização do ordenhador, e do local da ordenha, o manejo do gado nas propriedades, além do nível de tecnificação adotado na propriedade, são medidas e ações importantes que vão influenciar em todo processo da cadeia leiteira.

No ano de 2012, entre os estados, Minas Gerais manteve o primeiro lugar no "ranking" da produção leiteira, representando $28 \%$, do total produzido, seguido pelo Rio Grande do Sul, com 13\%, Paraná com 12\% e Goiás com 11\% (SEAB - Secretaria de Estado da Agricultura e do Abastecimento, 2014).

Em Goiás a produção leiteira é de 3,482 bilhões de litros, com participação de $10,9 \%$. Jataí foi o principal produtor goiano de leite e o 3 으 no ranking nacional, com 141,403 milhões de litros. Entre os 10 maiores municípios brasileiros figuraram ainda Morrinhos, em 40 lugar, com 128,8 milhões de litros, e Piracanjuba em 7ㅇ lugar com 117,936 milhões de litros (SEGPLAN, 2012).

Objetivou se verificar a composição da silagem de milho a qualidade do leite dos produtores de Morrinhos, bem como, avaliar se estão dentro dos critérios instruídos pela IN 62 .

\section{MATERIAL E MÉTODOS}

O presente trabalho foi conduzido em 10 propriedades leiteiras localizadas na região de Morrinhos, escolhidas por acaso, a região está localizado nas coordenadas geográficas 17연 $52^{\prime \prime}$ de Latitude S e 49 05' 58" de longitude W. Segundo a classificação climática de Köppen-Geige o clima é tropical quente e seco. Foi aplicado um questionário para a coleta de informações, cuja finalidade foi à posterior identificação do grau de tecnificação da propriedade classificados em Especializado (ES), caracterizada pela prática do pré e pós-dipping, e Semi- Especializado (SE), não realize o pré e pós dipping, estes procedimentos são realizados antes e após a ordenha, e possuem o intuito de diminuir a quantidade de bactérias presentes no teto, e consequentemente no leite, e também reduzir incidência de mastite na vaca, de acordo com Lopes et al, 2013 as 
soluções mais utilizadas e eficientes são a base de iodo e clorexidine a $0,5 \%$. Na mesma ocasião foram coletadas amostras de silagens, em pontos distintos do silo, e acondicionadas em sacos plásticos lacrados a fim de evitar a entrada ou a circulação de oxigênio, e transportadas em caixas de isopor, e posteriormente encaminahdas para o laboratório de microbiologia do Instituto Federal Goiano Campus Morrinhos, onde foi determinado o pH conforme o método proposto por Silva \& Queiroz (2002). As amostras foram submetidas à pré-secagem a $60^{\circ} \mathrm{C}$, durante 72 horas, em seguida foram moídas em moinho com faca tipo "Willey" com peneira de $1 \mathrm{~mm}$ e armazenadas em recipientes de plástico, devidamente lacrados, para determinação de MS (Método de 934,01; AOAC, 1990); MO determinada pelas cinzas (Método de 924,05; AOAC, 1990); e PB obtida pela determinação do $\mathrm{N}$ total, utilizando a técnica de micro-Kjedhal (Método de 920,87; AOAC, 1990). Os dados de análises do leite foram fornecidas pela Complem (Cooperativa mista dos produtores de leite de Morrinhos), sendo que os mesmos foram analisadas pelo laboratório de qualidade do leite da Universidade Federal de Goiás, utilizando o método da espectroscopia do infravermelho próximo (NIRS) para determinação da proteína e gordura do leite, a CCS e CBT foram determinados segundo o princípio da citometria de fluxo. Foi utilizado o programa estatístico SAS 9.22002 para obter os resultados estatísticos.

\section{RESULTADOS E DISCUSSÕES}

Na tabela 1 são apresentados os valores médios da silagem de milho referentes ao $\mathrm{pH}$, matéria seca (MS), cinzas e proteína bruta (PB), segundo os níveis de tecnificação adotado.

Tabela 1. Valores médios obtidos de $\mathrm{pH}$, matéria seca (MS), cinzas e proteína bruta (PB) na matéria seca das silagens de milho segundo os níveis de tecnificação.

\begin{tabular}{lcccc}
\hline Nível de tecnificação & $\mathrm{pH}$ & $\mathrm{MS} \%$ & Cinzas & PB \\
\hline ES & 3,73 & 31,86 & 8,41 & 7,30 \\
SE & 3,61 & 33,26 & 8,01 & 7,16 \\
\hline
\end{tabular}

$\mathrm{O} \mathrm{pH}$ e os teores de cinza estão relacionados com a qualidade da silagem, por sua vez, MS e PB relacionam se a composição nutritiva que influencia na composição do leite. Para Almeida (2013), um pH para manter a silagem bem conservada varia 3,7 a 4,2.

Os valores médios de cinza encontrado nas propriedades foram acima de 8, para Novinski et al (2013), valores acima de $6 \%$ de cinzas pode indicar possíveis contaminações do silo por terra, prejudicando a qualidade da silagem. Os elevados teores de cinza nas gramíneas podem contribuir para a menor digestibilidade da matéria seca (FUKUMOTO, et al. 2010).

De acordo com Pereira (2013), o teor de matéria seca adequada está entre 33 a 35\%, no entanto Demarchi (2001) considera aceitável uma variação de 30 a 35\%. Em um trabalho realizado com silagem de milho feito por Mizubuti (2002), observa valores de 23,22 a 39,60\%.

Com relação aos valores de proteína bruta, Almeida (2013) avaliou a qualidade da silagem de diferentes híbrido de milho e encontrou valores de PB entre 6,28 e 7,28\%.

Os resultados apresentados na tabela 2 referem-se ao nível de tecnificação e aos valores de gordura, proteína, CCS e CBT do leite de vacas alimentadas com silagem de milho. 
Tabela 2. Médias, desvio padrão, valores mínimos e máximos de gordura, proteína bruta, contagem de células somáticas (CCS) e contagem bacteriana total (CBT) do leite, segundo os níveis de tecnificação.

\begin{tabular}{llllll}
\hline \multicolumn{5}{c}{ Especializado } \\
\hline Variável & Amostras & Média & Desvio Padrão & Mínimo & Máximo \\
& & & & \\
\hline Gordura & 5 & 3.96 & 0.26 & 3.64 & 4.34 \\
Proteína bruta & 5 & 3.47 & 0.46 & 3.12 & 4.28 \\
CCS & 5 & 254.20 & 130.03 & 137.00 & 483.00 \\
CBT & 5 & 220.20 & 206.40 & 19.00 & 479.00 \\
\hline \multicolumn{7}{l}{} & \multicolumn{5}{l}{ Semi-Especializado } & & \\
\hline Variável & Amostras & Média & Desvio Padrão & Mínimo & Máximo \\
& 5 & & & & \\
\hline Gordura & 5 & 3.68 & 0.28 & 3.27 & 4.07 \\
Proteína bruta & 5 & 3.40 & 0.49 & 3.07 & 4.27 \\
CCS & 5 & 392.40 & 257.08 & 139.00 & 750.00 \\
CBT & 5 & 105.80 & 135.10 & 22.00 & 337.00 \\
\hline
\end{tabular}

Observou-se que a gordura, a CCS e a CBT do leite foram influenciados pelo nível de tecnificação das propriedades. Provavelmente os menores valores de gordura das vacas que estavam no sistema semi especializado ocorreu devido maiores teores de CCS, segundo Pereira et al. (1999), vacas com elevadas CCS mostram menores teores de gordura, além de maiores proporções de ácidos graxos de cadeia curta, por ação de lipases leucocitária e do próprio epitélio secretor mamário. Esta lipólise dos glóbulos de gordura expõe os triglicerídeos à ação das próprias lipases, acarretando elevação de ácidos graxos livres e o aparecimento de rancidez no leite. Segundo Vargas et al. (2014) não há correlação significativa entre CCS e CBT, o que reforça os diferentes comportamentos do úbere frente aos agentes causadores da mastite subclínica, ou microbiota residente.

A tabela 3 refere-se aos valores exigidos pela Instrução Normativa 62 para garantir leite de qualidade no mercado.

Tabela 3. Valores de gordura, proteína, CCS e CBT do leite cru refrigerado segundo critérios da Instrução Normativa 62 de 29 de dezembro de 2011, regulamentados pelo Ministério da Agricultura, pecuária e abastecimento.

\begin{tabular}{lc}
\hline Requisitos & Valores \\
\hline Gordura & $3,0 / 100 \mathrm{~g}$ (min.) \\
Proteína & $2,9 / 100 \mathrm{~g}(\mathrm{~min})$. \\
CCS & $500.00 \mathrm{CS} / \mathrm{ml}$ (máx.) \\
CBT & 300.00 UFC/ml (máx.) \\
\end{tabular}

Os teores de gordura e proteína estão acima dos limites mínimos exigidos, e os valores de CCS e CBT estão abaixo dos limites máximos. Dessa forma todas as variáveis estão dentro dos padrões exigidos pela IN 62 . 
A variável gordura foi maior no sistema ES, segundo Pereira (2001), o acetato é o principal ácido graxo percursor da gordura no leite, alta quantidade de MS na dieta estimula a ruminação e secreção salivar, com isso ocorre aumento no pH do rúmen, e conseqüentemente a produção de acetato é estimulada. Apesar de não ter sido relatado no trabalho, foi observado que as propriedades que possuíam nível de tecnificação ES forneciam mais alimento concentrado, provavelmente esse fato contribuiu para elevar o teor de MS da dieta total, justificando o maior teor de gordura no nível em questão. Simili et al. (2007) enfatiza que os valores de gordura devem obter uma média de 3,5\%. Segundo Fonseca (2005) e Jácome (2012), o leite apresenta uma variação normal em sólidos totais, fatores como, genética, raça, número de ordenhas, fase de lactação, fatores externos do ambiente. E necessário que no momento da coleta da amostra de leite seja feita a homogeneização do recipiente onde será retirada a amostra, pois a gordura possui densidade menor que água , se acumulando na superfície, o que pode ocasionar possíveis erros de quantidade de gordura na amostra, obtenção assim maior confiabilidade dos resultados.

O valor de CCS foi maior no sistema SE, ou seja, a ausência do pré e pós dipping influenciaram no nível de contaminação. Elevada CCS é sinal de infecção na glândula mamária conhecida como mastite, de acordo com Anklam (2011), a mastite está entre os principais problemas relacionados à atividade leiteira.

A CCS é uma infecção da glândula mamária, causada por contaminação de microorganismos indesejáveis, como forma de defesa, ocorre migração de células do sangue para a glândula mamária o que gera aumento do número de células somáticas no leite. Essa característica está relacionada ao cuidado sanitário das glândulas mamárias de vacas leiteiras e correto manuseio dos equipamentos de ordenha (MELO, et al. 2013).

Segundo Paula et al. (2004), elevada CCS indica perda de produção e baixa CCS boa saúde da glândula mamária. Segundo Fagan et al. (2008) o número e a fase de lactação dos animais ordenhados vão influenciar no número de CCS. Alta CCS no leite reduz a qualidade e o rendimento dos produtos lácteos, assim como a vida de prateleira (ALMEIDA, 2013).

$E m$ relação à $C B T$ houve resultados maiores no $E S$, através desse resultado conclui-se que o nível tecnológico da propriedade não pode ser utilizado como parâmetro isolado para avaliação da qualidade do leite. A maioria das propriedades não realizam os procedimentos de forma correta, eram utilizados 2, ou até mesmo 1 papel toalha por vaca para fazer a limpeza dos tetos, o que ocasionou ineficiência da higienização, e na limpeza das instalações, bem como do local de ordenha, o que pode ter contribuído para a diminuição da qualidade do leite. O procedimento do pré e pós dipping realizado de forma inadequada pode se transformar em uma fonte de microrganismos indesejáveis. Todos os procedimentos realizados antes, durante e após ordenha devem ser considerados para obter um leite com melhor qualidade.

A CBT avalia a qualidade microbiológica do leite (VENANCIO, 2013). A saúde da glândula mamária, a higiene de ordenha, o ambiente em que a vaca fica alojada e os procedimentos de limpeza do equipamento de ordenha são fatores que afetam diretamente a contaminação microbiana do leite cru (ALMEIDA, 2013).

Almeida (2013) analisou a implantação de boas práticas de ordenha e à manutenção e higienização dos equipamentos de ordenha observou uma redução média de $93,4 \%$ na CBT e $74,3 \%$ na CCS.

A quantidade de proteína bruta foi igual a 3,4 no sistema ES e SE, proteína é o componente do leite que menos possui variação em relação à dieta, segundo Jácome, (2012) ela pode variar até 0,2 unidades percentuais.

Melo et al (2013), estudando a qualidade do leite tipo C e cru refrigerado em sistema leiteiro do sudeste goiano, observou que a porcentagem de proteína bruta obteve valores com variação de 3,17 a 3,22 não diferindo estatisticamente entre si. Aumento na concentração de 
proteína do leite é obtido quando se eleva sua concentração na alimentação, resultando em aumento da energia disponível.

\section{CONCLUSÕES}

A silagem de milho é de boa qualidade. A ausência da prática do pré é pós dipping afetou negativamente a qualidade do leite. O sistema especializado apresentou maior presença de bactérias no leite. Os valores de CCS, CBT, teores de gordura e proteína bruta estão dentro dos limites máximos exigidos pela IN 62.

\section{REFERÊNCIAS}

ALMEIDA, Thamara Venâncio de. Parâmetros de qualidade do leite cru bovino: contagem bacteriana total e contagem de células somáticas. Universidade federal de Goiás escola de veterinária e zootecnia programa de pós-graduação em ciência animal. Goiânia, GO. 2013.

ANKLAM, Daniel Ivanei. Gestão e Planejamento da atividade leiteira em unidades de produção familiar: comparação entre sistemas de manejo e seus resultados.46 f. Tese (Graduação). Faculdade de ciências econômicas departamento de ciências econômicas. Universidade Federal do Rio Grande do Sul.Porto Alegre, RS. 2011

AOAC, 1990. Official Methods of Analysis, (15th edn.). Association of Official Analytical Chemists, Arlington, VA .

BRASIL. Ministério da Agricultura, Pecuária e Abastecimento. Instrução normativa no 62, de 29 de dezembro de 2011.

DEMARCHI, J.J. Pontos críticos na amostragem e interpretação das análises bromatológicas para silagem de milho. 24 abr. 2001.

DIAS, Sandra Duarte da Fonseca. Efeito de diferentes regimes alimentares sobre a qualidade do leite produzido. Universidade dos açores departamento de ciências agrárias. Dissertação de mestrado em produção animal. Dissertação de Mestrado. Escola Superior Agrária de Castelo Branco. 2006

FERNANDES, Leonice Luchetti Vieira. Produção e qualidade do leite: um estudo de caso na Apelu.52 f. Tese (Especialização). Curso de especialização em gestão de negócios financeiros. Escola de Administração- Universidade Federal do Rio Grande do Sul. Porto Alegre, RS. 2011.

GOIÁS. Secretaria de Estado de Gestão e Planejamento. Goiás em dados 2012. Goiânia, GO, 107 p. 2013.

JÁCOME, Daniele Canabrava. Avaliação da qualidade do leite cru em diferentes sistemas de produção e épocas do ano. 48 f. Tese (Mestrado). Programa de Pós-Graduação do Mestrado Profissional em Zootecnia. Universidade Federal de Viçosa. Viçosa, MG. 2012.

LOPES, L.O. et al. Eficiência de desinfetantes em manejo de ordenha em vacas leiteiras na prevenção de mastites. Ver. Científica Eletrônica de Medicina Veterinária. Ano XI-n ${ }^{\circ} 21$. Julho. 2013. 
MELO, A.F. et al. Qualidade do leite cru tipo $C$ e refrigerado em sistemas leiteiros tradicionais do Sudoeste Goiano. Revista. Inst. Laticínios Cândido Tostes, Juiz de Fora, v. 68, n³95, p. 26-32, Nov/dez.,2013. https://doi.org/10.5935/2238-6416.20130045

NOVINSKI, Charles Ortiz. Composição de micotoxinas e bromatologia de silagens de milho em silos de grande porte utilizando imagens em Infravermelho. Universidade Federal do Paraná. Dissertação de Mestrado. Pós Graduação em Ciências Veterinárias, área de Concentração em Nutrição Animal e Alimentação Animal.Curitiba, PR. 2013.

OLIVEIRA, J.S. et al. Adaptabilidade e estabilidade de cultivares de milho destinados à silagem em bacias leiteiras do estado de Goiás. Pesq. Agropec. Tropical 37(1): 45-50, mar. 2007

PEREIRA, B. M. Avaliação da qualidade da silagem de híbridos de milho (Zea mays. L.) cultivados no Distrito Federal. Universidade de Brasília. Faculdade de Agronomia e Medicina Veterinária. Brasília, DF. Julho. 2013.

SAS Institute Inc. (2002) Statistical Analysis System user's guide. Version 9.0. Cary, Statistical Analysis System Institute. 513p.

SEAB. Secretaria de Estado da Agricultura e do Abastecimento. DERAL - Departamento de Economia Rural. Análise da Conjuntura Agropecuária Ano 2013/14. Leite. 2014.

SILVA, D. J. et al. Análise de alimentos métodos químicos e biológicos. Viçosa: UFV, 235p. 3.ed. 2002.

SIMILI, F.F. et al. Como os alimentos podem afetar a composição do leite das vacas. Pesquisa \& Tecnologia, vol. 4, n.1 Jan-Jun 2007.

VARGAS, D. P. Correlações entre contagem de células somáticas e parâmetros físico-químicos e microbiológicos de qualidade do leite, Ciência Animal brasileira, Goiânia, v.15, n.4, p. 473-483 out./dez. 2014. http://dx.doi.org/DOI: 10.590/1809-6891v15i420637

ZOCCAL, R. et al. Diagnóstico da pecuária de leite nacional. Estudo Preliminar Contribuição para o Plano Pecuário 2012. Dezembro, 2011. 